\title{
Beau lines associated with COVID-19
}

\author{
Saud Alobaida MD, Joseph M. Lam MD
}

Cite as: CMAJ 2020 September 8;192:E1040. doi: 10.1503/cmaj.201619

A 45-year-old man presented with a horizontal groove over all his fingernails and toenails. The grooves were most noticeable over his great toenails bilaterally, with a horizontal groove $5 \mathrm{~mm}$ from the proximal nailfold (Figure 1). Three and a half months previously, he had been given a diagnosis of coronavirus disease 2019 (COVID-19) after a positive nasopharangeal swab polymerase chain reaction test, owing to symptoms of diarrhea, fever and shortness of breath, which lasted for 10 days and did not require admission to hospital.

The cutaneous findings associated with COVID-19 have been classified into 5 distinct patterns: a maculopapular eruption, chilblain lesions, urticarial lesions, a vesicular eruption and livedo reticularis and necrosis. ${ }^{1}$ Some of these findings, such as the vesicular eruption, appear early in the disease course; others are seen later, such as the chilblain pattern. ${ }^{2}$

Beau lines are transverse grooves in the nail plate that result from transient interruption of the growth of the proximal nail matrix. ${ }^{3}$ They are often noticed 2-3 weeks after a systemic insult and their appearance parallels the length of time needed for the nail to grow past the proximal nailfold. As the toenails grow at a rate of about $1.62 \mathrm{~mm}$ per month, the distance of the Beau lines from the proximal nailfold in our patient reflects the timing of severe acute respiratory syndrome coronavirus 2 (SARS-CoV-2) infection. ${ }^{4}$ Other causes of Beau lines include localized trauma and systemic triggers such as febrile illness, severe malnutrition, pemphigus, Raynaud disease, Kawasaki disease and chemotherapy. There is no specific therapy for Beau lines, as they selfresolve if the underlying condition has resolved.

\section{References}

1. Galván Casas C, Català A, Carretero Hernández G, et al. Classification of the cutaneous manifestations of COVID-19: a rapid prospective nationwide consensus study in Spain with 375 cases. Br J Dermatol 2020;183:71-7.

2. Ladha MA, Dupuis C. SARS-CoV-2-related chilblains. CMAJ 2020;192:E804.

3. Chu NS, Wu IC, Chen LT, et al. Beau's lines in nails: an indicator of recent Docetaxel and 5-FU use. Kaohsiung J Med Sci 2018;34:181-3.

4. Yaemsiri S, Hou N, Slining MM, et al. Growth rate of human fingernails and toenails in healthy American young adults. J Eur Acad Dermatol Venereol 2010; 24:420-3.

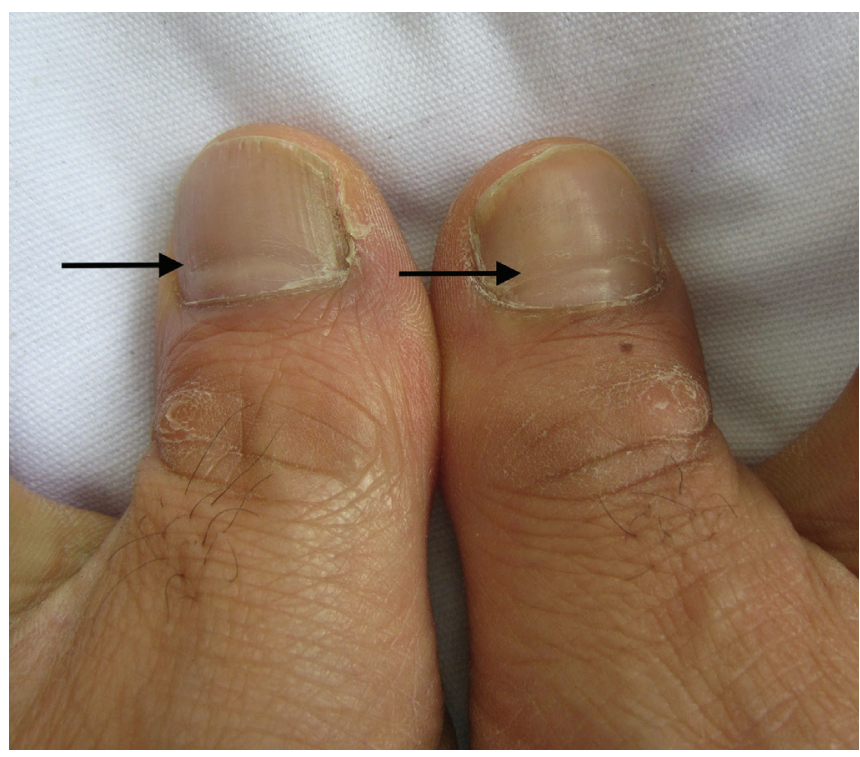

Figure 1: Horizontal longitudinal grooves across the great toenails bilaterally (arrows) measured $5 \mathrm{~mm}$ from the proximal nailfold.

\section{Competing interests: None declared.}

This article has been peer reviewed.

The authors have obtained patient consent.

Affiliations: Division of Pediatric Dermatology (Alobaida), Department of Pediatrics, and Departments of Paediatrics and Dermatology and Skin Science (Lam), University of British Columbia, Vancouver, BC

Correspondence to: Joseph Lam, joseph.mc.lam@gmail.com

Clinical images are chosen because they are particularly intriguing, classic or dramatic. Submissions of clear, appropriately labelled highresolution images must be accompanied by a figure caption. A brief explanation (300 words maximum) of the educational importance of the images with minimal references is required. The patient's written consent for publication must be obtained before submission. 